\title{
Leer a Paulo Freire es habitar el tiempo del anhelo Piedad Ortega-Valencia ${ }^{1}$
}

\author{
Somos educadores y educadoras \\ Radiantes, esperanzadores. \\ como lámparas abriendo paisajes, \\ pulsando arpas, guitarras y violines. \\ Somos educadores y educadoras \\ de la fábula y el ensueño \\ con alas y espigas. \\ Somos palabra \\ en aurora y en poniente. \\ Somos también \\ este tiempo sin tregua: \\ De esperanzas remendadas. \\ De cementerios al viento. \\ De memorias en fosas. \\ Somos también \\ Mudos mendigos \\ De húmedos alientos. \\ Somos en este tiempo \\ Campanas, timbres, acordeones y marimbas, \\ Somos una bandada de alondras \\ en canciones de lluvia. \\ Somos luciérnagas \\ en cantos de cigarras.
}

\footnotetext{
${ }^{1}$ Profesora de la Licenciatura en Educación Comunitaria con énfasis en Derechos Humanos, de la Maestría en Educación de la Facultad de Educación y del Doctorado Interinstitucional de la Universidad Pedagógica Nacional. Integrante de los siguientes espacios: grupo de investigación Educación y Cultura Política; semillero de investigación en Pedagogías Críticas, Memorias y Alteridad, grupo de trabajo de Clacso Educación Popular y Pedagogías Críticas; Colectivo de Educación Popular Dimensión Educativa (Colombia). Correo electrónico: piedadortegava@yahoo.es
} 
Paulo Freire hoy hace presencia en una cantera de profesores, jóvenes universitarios, militantes políticos, artistas, trabajadores culturales, emprendedores de la memoria y educadores populares. Sujetos de esta época, de estos tiempos y de estas luchas que en medio de la adversidad y de situaciones conflictivas le apuestan a la fuerza emancipadora de nucleamientos formativos y organizativos, la cual se moviliza en torno a unas construcciones dialógicas, reflexivas, deliberantes y de compromiso. Estas apuestas vinculares pretenden resignificar la herencia educativa de este pensador latinoamericano nuestro. Por ello, el telar de la pedagogía en Paulo Freire es la expresión de la diferencia intergeneracional, de las múltiples ecologías políticas de saberes, de proyectos filiales, de narrativas biográficas y trayectorias, en las que se encuentra una disposición para un trabajo colectivo desde los espacios de actuación de cada uno.

Esta reflexión intenta recoger el legado de Paulo Freire ${ }^{2}$ alrededor de la actualidad de su obra pedagógica, la cual invitamos a leer por su vitalidad y firmeza, como lo expresa el filósofo Joan Carles Mélich (2020):

No es una firmeza dogmática o fanática, sino inquietante, es una firmeza que golpea directamente no solo la mente del lector, sino todo su cuerpo, es una firmeza que golpea su existencia. Es el lector el que se convierte en frágil al leerlo, y se trata de subrayar esta fragilidad. La firmeza del texto, como ya se ha dicho, consiste en la resistencia al tiempo. (p. 213)

Exploramos en Freire la capacidad de provocar reflexiones pedagógicas las cuales nos ha permitido construir nuevos y renovados caminos para la acción formativa, haciendo posible en los(as) educadores(as) populares la expresión de lo político-pedagógico, como una tarea anudada a las transformaciones que se puedan orientar, su carácter autopoiético, una actitud crítica en torno a los modos de ejercicio del poder, la apertura dialógica con actores de instituciones y espacios populares y las creaciones pedagógicas que afirman existencialmente a los actores del proceso formativo acerca de su historia y autonomía. Horadamos en este equipaje y nos encontramos con la presencia fundante de la lectura y escritura en su propia vida como modos de subvertir el mundo. Mouawad (2011) lo recoge con este bello planteamiento en su obra de teatro:

Yo soy responsable de usted y usted es responsable de mí. Nosotros no quisimos ni la guerra ni la violencia, pero hicimos la guerra, y fuimos violentos. Lo único que nos queda es nuestra dignidad

\footnotetext{
${ }^{2}$ Mi gratitud a Lola Cendales, maestra y amiga, por su acogida en el Colectivo de Educación Popular Dimensión Educativa; igualmente, a Marco Raúl Mejía, Alfonso Torres, Alfredo Ghiso y Fernando Torres, porque cada uno de ellos, a su manera, me han permitido dibujar el horizonte de la educación popular, encontrarnos y celebrar la amistad. Amistad que está presente en esta reflexión. Un canto para nombrar a los educadores populares que han partido para estar en otros espacios espirituales: Mario Peresson, Mario Acevedo, German Mariño y Graciela Bolaños.
} 
(...) hablándole como le hablo doy testimonio de mi promesa dada a una mujer que un día me hizo comprender la importancia de abandonar la miseria: aprende a leer, a escribir, a contar, aprende a pensar. (p. 146)

De modo que Freire posiciona la pedagogía como un saber teórico-práctico en tensión permanente, en tanto los sujetos, saberes, los fines, los contextos, las experiencias, las intencionalidades y los espacios, entre otros aspectos, se instituyen en modulaciones posibles para potenciar los procesos de formativos que se requieren activar. En esa medida las prácticas pedagógicas, institucionales e instituyentes (populares, comunitarias) exigen de la construcción de repertorios políticos sostenidos desde una ética de la responsabilidad, asumida esta como cuidado en un anhelo constante de justicia.

Develar las tensiones presentes en la pedagogía nos permite preguntarnos: ¿qué decir, qué nombrar y qué narrar de Paulo Freire, nuestro pedagogo crítico latinoamericano? ¿En qué contexto social, político, cultural y educativo se sitúa la producción de sus obras pedagógicas? ¿Desde dónde se asumen sus construcciones, en qué escenarios, con quienes y con qué particularidades? ¿Cuáles son los puentes generacionales que teje el legado de Paulo Freire de las viejas generaciones con las de nuevos educadores(as)? ¿Qué recepcionan y resignifican del pensamiento de Paulo Freire hoy los(as) maestros(as) y los(as) educadores(as) populares? ¿Qué transformaciones se están haciendo tanto en la construcción de saberes como en el despliegue de problemas, potencialidades, prácticas y procesos de educación popular?

Pedagogía de la pregunta diría Freire para conmemorar su natalicio. Por lo tanto, hemos decidido desplegar nuevamente su pensamiento pedagógico para que nuevas generaciones de maestros(as) y educadores(as) reconozcan sus proyectos y trayectos en cada uno de los libros que escribió y que tan amorosamente puso a disposición de sus lectores y lectoras; muchos de estos y estas, los condenados de la tierra ${ }^{3}$ (Fanón, 1986), nombre del libro que fue referencia vital en Paulo Freire en la escritura de su Pedagogía del oprimido. Hoy los rostros del oprimido son los sin tierra, los sin casa, los sin escuela, los sin comida, los sin empleo, los sin anhelos; o como los nombra el poeta guatemalteco Humberto Ak'abal (2009) en los siguientes versos:

\footnotetext{
${ }^{3}$ De Frantz Fanón (1925-1961), psiquiatra, filósofo y escritor argelino. Otra de sus obras de gran relevancia sobre los efectos de la raza y de las relaciones de sujeción en nuestra cultura es su libro Piel negra, máscaras blancas (1973).
} 


\section{Lejanía}

En este país pequeño

Todo queda lejos:

La comida,

Las letras,

La ropa...

\section{Agujeros}

A mi ropa

Le cuelgan

Algunos agujeros.

Por ellos se cuela

El frío de la pobreza.

Aquí están entonces sus libros como ofrendas. Invitamos a retornar a ellos, maravillarnos de nuevo, construir los rituales para el diálogo; a disponerlos en el salón de clase, en un parque, en algún rinconcito de la casa o de la biblioteca comunitaria; acariciarlos con una voz pausada y serena y donarlos en la hospitalidad de una experiencia compartida de lectura:

- ¿Extensión o comunicación? La concientización en el medio rural.

-Educación como práctica de la libertad.

- La educación en la ciudad.

- Política y educación.

- La importancia de leer y el proceso de liberación.

- A la sombra de este árbol.

-El grito manso.

- Pedagogía del oprimido.

- Pedagogía de la autonomía: saberes necesarios para la práctica educativa.

- Pedagogía de la esperanza: un reencuentro con la pedagogía del oprimido.

- Hacia una pedagogía de la pregunta: conversaciones con Antonio Faúndez.

- Pedagogía de la tolerancia.

- Pedagogía de la indignación.

En este repertorio de libros está también su producción epistolar, la cual tiene un registro bellamente literario: Cartas a quien pretende enseñar; Cartas a Cristina: reflexiones sobre mi vida y mi trabajo; Cartas a Guinea-Bissau: apuntes de una experiencia pedagógica en proceso. Cartas abiertas, precisas, justas y dignificantes del trabajo de los(as) maestros(as) y educadores(as) populares. 
Tendríamos que agregar los cientos de entrevistas, conferencias, ensayos, conversaciones, videos y audios que circulan en innumerables bibliotecas y centros de documentación con sus exposiciones coherentes y consistentes con su práctica y sus itinerarios de vida. También resaltamos sus escritos con otros educadores, así como las biografías ${ }^{4}$ y las múltiples narrativas musicales y visuales que caminan con su nombre, en sellos y estampados.

En Freire encontramos entonces la posibilidad de resignificar sus construcciones epistémicas en contexto, y decimos esto porque la lectura constituye uno de sus planteamientos centrales, asumida como un proceso de alfabetización política. Freire (2008) lo argumenta de la siguiente manera:

El proceso de alfabetización de adultos, visto desde un punto de vista liberador, es un acto de conocimiento, un acto creador, en que los alfabetizandos desempeñan el papel de sujetos cognoscentes tanto como los educadores. Obviamente, entonces, los alfabetizandos no son vistos como vasijas vacías, meros recipientes de las palabras del educador. Desde este punto de vista, además, los alfabetizandos no son seres marginales que necesitan ser recuperados o rescatados. En lugar de ser vistos así, son considerados como miembros de la gran familia de los oprimidos para quienes la solución no está en aprender a leer historias alienadas, sino en hacer historia y ser hechos por ella. (pp. 72-73)

De este planteamiento se desprende La lectura del mundo precede a la lectura de la palabra. Esta tesis la recreamos con Estanislao Zuleta (2005), quien nos convoca a la lectura como trabajo, oficio, artesanía, técnica, sensibilidad y deseo:

Hay que tomar por lo tanto en su sentido más fuerte la tesis de que es necesario leer a la luz de un problema. Un problema es una sospecha y una esperanza. La sospecha de que existe una unidad y una articulación necesaria allí donde solo vemos algunos elementos dispersos, que solo podemos entender parcialmente; que se nos escapan pero que insisten como una herida abierta. Y la esperanza de que si logramos establecer esa articulación necesariamente quedará explicado algo que no lo estaba; quedará removido algo que impedía el proceso de nuestro pensamiento y funcionaba por lo tanto como un nudo en nuestra vida; quedará roto un lazo de aquellos que nos atan obligándonos a emplear toda nuestra energía, nuestra agresividad y nuestra libido, en lo que Freud llamaba una guerra civil sin esperanzas. El trabajo de la sospecha consiste en someter todos los elementos a una elaboración y a una crítica, que permita superar el poder de la fuerza (represión, ideología dominante, racionalización, etc.) que los mantiene dispersos, yuxtapuestos

\footnotetext{
${ }^{4}$ Referenciamos los siguientes: Freire y Macedo (1989); Freire y Shor (2014), Streck (20o8); Rodríguez-Brandao (2014); Osorio (2018); Kohan (2020); Revista Aportes, Dimensión Educativa (Colombia). Dos producciones audiovisuales abordan su biografía: i) Paulo Freire contemporáneo. https://www.youtube.com/watch?v=5s2Fmtr3FN8 y, ii) Paulo Freire. Serie Maestros de América Latina. https://www.youtube.com/watch?v=z4RxpqyjYmw
} 
o falsamente conectados. Leer a la luz de un problema es pues leer en un campo de batalla, abierto por una escritura y por una investigación. (p. 4)

De ahí la necesidad de indicar que su propuesta pedagógica potencia a los sujetos individuales y colectivos, incorpora la historia y las memorias como dinámicas de significación de la realidad socia, trabaja con la multiplicidad de saberes que se requieren en la formación de maestros(as) y educadores(as) y por, sobre todo, importante destacar que su pedagogía nos implica existencial y colectivamente. Estos rasgos presentes en todo acto formativo freiriano en la escuela o en procesos comunitarios, rurales y universitarios nos permiten afirmar que su pedagogía es políticamente emancipadora. El mismo lo enuncia con este argumento en Pedagogía de la indignación (2006):

Lo que quiero decir es lo siguiente: en la medida en que nos hagamos capaces de transformar el mundo, de poner nombre a las cosas, de percibir, de entender, de decidir, de escoger, de valorar, en último término, de eticizar el mundo, nuestro movimiento en él y en la historia envuelve, necesariamente, los sueños por cuya realización luchamos. De ahí, pues, que nuestra presencia en el mundo, que supone elección y decisión, no sea una presencia neutra. (p. 43)

Reafirmamos que la obra pedagógica de Freire constituye las directrices tanto de la educación popular como de la pedagogía crítica latinoamericana, las cuales configuran un rico universo acerca de la educación y la ética liberadora; pues Freire (2006) bellamente nos plantea que somos condicionados, pero no determinados:

Si soy puro producto de la determinación genética o cultural o de clase, soy irresponsable de lo que hago en el moverme en el mundo y si carezco de responsabilidad no puedo hablar de ética. Esto no significa negar los condicionamientos genéticos, culturales, sociales a que estamos sometidos. Significa reconocer que somos seres condicionados, pero no determinados. Reconocer que la historia es tiempo de posibilidad y no de determinismo, que el futuro, (...) es problemático y no inexorable. (p. 21)

Por supuesto, batallaremos contra este condicionamiento y tantos otros que reducen a veces nuestras capacidades de actuación. Batallaremos contra la inercia y la comodidad, la indiferencia y el olvido. Batallaremos contra los autoritarismos y las patologizaciones de la diferencia. Batallaremos contra la resignación y el fracaso. Batallaremos contra las narrativas que nos quieren imponer en estos tiempos de pandemia: la producción de miedos planificados, la construcción de enemigos y la higienización en las relaciones sociales. Situaciones problémicas que nos exigen como tarea trabajar en torno al agenciamiento de prácticas en y desde la educación popular 
que posibilite relievar las expectativas de vida de los sujetos y sus colectividades; cuidar sus entornos, resignificar sus cotidianidades, atender sus urgencias existenciales, culturales y económicas; revitalizar el afecto en la confianza, en la solidaridad, en la responsabilidad y en la espiritualidad para que juntos podamos construir proyectos de vida digna y de vida justa para tiempos largos. Freire (2012) atiende los conflictos de su época y como testimonio elabora una bella proclama sobre el maestro:

No puedo ser profesor si no percibo cada vez mejor que mi práctica, al no poder ser neutra, exige de mí una definición. Una toma de posición. Decisión. Ruptura. Exige de mí escoger entre esto y aquello.

No puedo ser profesor en favor de quienquiera y en favor de no importa qué.

No puedo ser profesor en favor simplemente del hombre o de la Humanidad, frase de una vaguedad demasiado contrastante con lo concreto de la práctica educativa.

Soy profesor en favor de la decencia contra la falta de pudor, en favor de la libertad contra el autoritarismo, de la autoridad contra el libertinaje, de la democracia contra la dictadura de derecha o de izquierda.

Soy profesor en favor de la lucha constante contra cualquier forma de discriminación, contra la dominación económica de los individuos o de las clases sociales.

Soy profesor contra el orden capitalista vigente que inventó esta aberración: la miseria en la abundancia.

Soy profesor en favor de la esperanza que me anima a pesar de todo.

Soy profesor contra el desengaño que me consume y me inmoviliza.

Soy profesor en favor de la belleza de mi propia práctica, belleza que se pierde si no cuido del saber que debo enseñar, si no peleo por este saber, si no lucho por las condiciones materiales necesarias sin las cuales mi cuerpo, descuidado, corre el riesgo de debilitarse y de ya no ser el testimonio que debe ser de luchador pertinaz, que se cansa, pero no desiste. (pp. 97-98)

Aquí estamos entonces en este hermanamiento existencial, el cual nos invita a leer y a releer la obra pedagógica de Paulo Freire y, junto a ella, reconocer su biografía filosófica, poética, antropológica y educativa ${ }^{5}$ y permitirnos — con Gioconda Belli (2018) — decir que

escribir me ha permitido acceder al otro y la otra; me ha dado ojos para mirar más allá de mí misma, para entrar en otros cuerpos, saberme un ser múltiple, para aprender a querer y a dolerme

\footnotetext{
${ }^{5}$ Importante reconocer algunos de los trabajos sobre Paulo Freire en: Alfonso Torres, Alfredo Ghiso, Marco Raúl Mejía, Germán Mariño, Lola Cendales, Santiago Gómez (educadores colombianos); Walter Kohan, Adriana Puiggrós, Anahí Guelman, Mercedes Palumbo (educadores argentinos); Moacir Gadotti, Danilo Streck, Carlos Rodríguez Brandao, Nita Freire (educadores brasileros); Fabián Cabaluz, Jorge Osorio (chilenos).
} 
por la grandeza y miseria de nuestra especie, pero también para cuestionarlo todo, para rabiar a ratos sin entender, parafraseando a Rubén Darío, de dónde venimos y para dónde vamos. (p. 2o)

Aquí nos encontramos para cuidar la vida, con la luminosidad del canto que sabe a semilla y a cosecha; con la memoria de huracanes, lluvias, mares y ríos para humedecer el horror de la guerra; con la corteza de la poesía, para desnudar los miedos y las resistencias.

Aquí estamos, poblando de luciérnagas sus palabras para desafiar esta pedagogía del bonsái ${ }^{6}$ y esta educación del galpón que se está imponiendo como libreto en la formación de nuevas generaciones de profesores(as) y educadores(as) populares.

Aquí estamos, amasando sus palabras generadoras alrededor de la conciencia crítica, el diálogo de saberes, el inédito viable, la reflexividad en la acción, los círculos de la cultura, la naturaleza ética de la práctica, la pedagogía como resistencia...; y podríamos seguir rastreando en el acto de leer como gesto y movimiento de liberación que nos permite continuar empujando la esperanza en estos tiempos tan adversos, hostiles y crueles. Qué mejor promesa de lectura que traer de vuelta sus palabras:

No soy esperanzado por pura terquedad, sino por un imperativo existencial e histórico. (...) Mi esperanza es necesaria pero no es suficiente. Ella no gana la lucha, pero sin ella la lucha flaquea y titubea. Necesitamos la esperanza crítica como el pez necesita el agua incontaminada. (2011, p. 24)

Convocamos a encantarnos nuevamente con sus palabras, con renovados gestos, con una lúcida esperanza que nos permita activar y fortalecer las actuaciones sentipensantes que su propuesta pedagógica reclama. Y a partir de este reconocimiento de Freire, recordamos este texto del poeta español Federico García-Lorca (1931):

No solo de pan vive el hombre. Yo, si tuviera hambre y estuviera desvalido en la calle no pediría un pan; sino que pediría medio pan y un libro. Y yo ataco desde aquí violentamente a los que solamente hablan de reivindicaciones económicas sin nombrar jamás las reivindicaciones culturales, que es lo que los pueblos piden a gritos. Bien está que todos los hombres coman, pero que todos los hombres sepan. Que gocen todos los frutos del espíritu humano porque lo contrario es convertirlos en máquinas al servicio de Estado, es convertirlos en esclavos de una terrible organización social.

\footnotetext{
${ }^{6}$ Recreamos este planteamiento de Hugo Zemelman y Estela Quintar, para quienes la pedagogía del bonsái consiste en formar seres humanos armoniosos pero chiquitos, es decir, sin fuerza, sin capacidad de acción, sin imaginación. Pedagogía que produce sujetos desfondados sin fuerza, sin vitalidad. Sujetos destinados a obedecer y a seguir instrucciones. Estela Quintar (Salcedo, 2009), afirma: «La pedagogía del bonsái es el proceso formativo que va mutilando suave, responsable, ordenada y técnicamente la capacidad del pensar creativo» (p. 124).
} 
Yo tengo mucha más lástima de un hombre que quiere saber y no puede, que de un hambriento. Porque un hambriento puede calmar su hambre fácilmente con un pedazo de pan o con unas frutas, pero un hombre que tiene ansia de saber y no tiene medios, sufre una terrible agonía porque son libros, libros, muchos libros los que necesita y ¿dónde están esos libros? ${ }^{7}$

Este sueño de Lorca se recrea en las voces literarias de la escritora nigeriana Chimamanda Ngozi Adichie (2011) con su relato El peligro de una historia única; o en la lectura antirracista y feminista de Toni Morrison, la primera nobel de literatura afroamericana, quien en su discurso, narró lo siguiente:

La mujer es hija de esclavos, negra, americana y vive sola en una pequeña casa afuera del pueblo. Su reputación respecto de su sabiduría no tiene par y es incuestionable. Entre su gente ella es a la vez la ley y su transgresión. El honor y el respeto que le tienen va hasta mucho más allá de su pueblo; llega hasta la ciudad donde la inteligencia de los profetas rurales es una fuente asombrosa.

Un día a la mujer la visitan unos jóvenes que vienen con la intención de desaprobar su clarividencia y poner en evidencia el fraude que creen que ella es. Su plan es simple: entran en su casa y le hacen una única pregunta, cuya respuesta manifiesta la diferencia que tienen con ella, una diferencia que ven como una profunda ineptitud: su ceguera. Se le paran enfrente y uno le dice: «Anciana, tengo en mi mano un pájaro. Dígame si está vivo o muerto».

Ella no contesta y repiten la pregunta: «¿Está vivo o muerto el pájaro que tengo?»

Tampoco contesta. Es ciega y no puede ver a sus visitantes, mucho menos lo que tienen en sus manos. No sabe el color de su piel, de dónde vienen ni si son hombres o mujeres. Solo conoce sus motivos. El silencio de la mujer es tan largo que los jóvenes tienen dificultad para aguantar la risa.

Finalmente habla y su voz es suave, pero severa. «No sé», dice; «no sé si el pájaro que tienen está vivo o muerto, lo único que sé es que está en sus manos. Está en sus manos».

Está en nuestras manos, es decisión nuestra, volver a leer a Freire. Porque leerlo es habitar el tiempo del anhelo, un tiempo compartido y vinculante con las texturas de nuestras existencias. Es construir y sostener los vínculos comunitarios en la radicalidad de su política que dialoga con los conflictos de esta época, sus rebeldías y militancias. Es recuperar su inédito viable y hacerlo nuestro, tan nuestro que nos permita compartir una humanidad que hoy en nuestro país está siendo despojada para posibilitar enraizarnos en cuerpos fraternos, cuerpos que aman, cuerpos que abrazan, cuerpos que sienten miedo. Cuerpos disruptivos, transgresores, subversivos. Cuerpos en comunidad.

\footnotetext{
${ }^{7}$ El texto que Federico García Lorca leyó en la inauguración de la biblioteca de su pueblo, Fuente Vaqueros, en septiembre del año 1931, es una de las defensas más fuertes, sencillas y emotivas que pueden encontrarse sobre la importancia de las bibliotecas.
} 
Freire es memoria y es nuestro porvenir, es nuestro respiro y horizonte, los cuales nos permiten seguir apostándole a la educación liberadora, a la educación popular, la educación comunitaria, la educación rural, las educaciones propias, la etnoeducación, las pedagogías críticas, las pedagogías feministas, las ecopedagogías, las geopedagogías; en suma, toda una cantera de pedagogías insumisas, provocadoras, deseantes y problematizadoras.

Gracias Freire y a todas las generaciones de educadores(as) populares ${ }^{8}$ que han hecho posible que su pensamiento sobre la educación liberadora siga siendo una poética de la libertad, de la resistencia, de la autonomía y de la indignación. Necesitamos de una educación que lleve al hombre y a la mujer a nuevas errancias e invenciones frente a los problemas de este tiempo y de estos espacios formativos; que nos permitan fecundar nuestras potencias de soñar y de actuar en un diálogo con muchas voces; un diálogo territorializado, donde el cuerpo, los afectos, la memoria, la historia, la justicia, la dignidad, los conflictos y los vínculos sean parte de nuestras rebeldías cotidianas. Recogemos tu legado y lo resignificamos con:

La fuerza de nuestras voces, saberes y prácticas.

La lucidez de nuestros pensamientos y nuestras luchas.

La vitalidad de nuestras juntanzas diversas y transgresoras.

La sabiduría de lo común con sus afectos, cuidados y conflictos.

La generosidad de la resistencia en procura de la justicia y la dignidad.

La amorosidad del diálogo intergeneracional que se teje entre solidaridades.

La urgencia por hacernos responsables de tantos y tantas jóvenes, mujeres, hombres, niños y niñas víctimas de la violencia política, de la violencia social, cultural y simbólica que produce el Estado; la que sigue estando anclada en las realidades que nos atraviesan y en las que hoy apenas si nos permiten sobrevivir a esta violencia de la desesperanza.

Recogemos tu legado sentipensante en nuestros cantos, como este que interpreta la cantautora argentina Teresa Parodi:

\footnotetext{
${ }^{8}$ Generaciones que hoy te recuerdan en la apertura de nuevos caminos y en la construcción de un proyecto histórico de un mundo común. Nuestra gratitud a la Plataforma latinoamericana 100 voces por Freire, organizada por el Centro Internacional de Investigaciones y Clacso; al Consejo de Educación Popular de América Latina y el Caribe (Ceaal). En Colombia: Centenario Paulo Freire, coordinado por la Movilización Social por la Educación, iniciativas universitarias como las agenciadas por la Universidad Pedagógica Nacional: Cátedra doctoral Paulo Freire, las educaciones y las pedagogías emancipadoras en el siglo XXI, coordinada por los profesores Alfonso Torres y Piedad Ortega; Cátedra Paulo Freire coordinada por el colectivo de educadores populares.
} 


\section{Creo}

Necesito hermano que me digas puedo

Con las mismas ganas que lo digo yo

Necesito hermano que nos encontremos

En una mirada, en una canción.

Y creo en vos y en mí, en mí y en vos

En la complicidad de la ilusión

No dejo de creer en vos y en mí

En mí y en vos.

Llevo en la guitarra un amor urgente

Que me da coraje con obstinación.

La esperanza invicta me sostiene siempre

Tan intensamente que no tengo opción.

Porque creo en todo lo que nos debemos.

Porque creo en ésta nuestra rebelión, de amorosa vida, de amorosa fuerza de amorosa rabia, de amoroso amor.

\section{Referencias}

Ak'abal, H. (2009). Grito. Editorial Maya.

Belli, G. (2018). Rebeliones y revelaciones. Txalaparta.

Fanón, F. (1986). Los condenados de la tierra. Fondo de Cultura Económica.

Freire, P. (1970). Pedagogía del oprimido. Fondo de Cultura Económica.

Freire, P. (2006). Pedagogía de la indignación. Morata.

Freire, P. (2008). El proceso de leer y el proceso de liberación. Siglo XXI.

Freire, P. (2011). Pedagogía de la esperanza: un reencuentro con la pedagogía del oprimido. Siglo XXI.

Freire, P. (2012). Pedagogía de la autonomía: siete saberes necesarios para la práctica educativa. Siglo XXI.

Freire, P., \& Macedo, D. (1989). Alfabetización lectura de la palabra y lectura de la realidad. Paidós.

Freire, P., \& Shor, I. (2014). Miedo y osadía: la cotidianidad del docente que se arriesga a practicar una pedagogía transformadora. Siglo XXI.

García-Lorca, F. (1931). Alocución al pueblo de Fuentes Vaqueros. http:// www.cervantesvirtual.com/obra-visor/alocucion-al-pueblo-de-fuente-vaqueros-discurso- 
leido-por-la-inaguracion-de-la-biblioteca-publica-de-fuente-vaquerosseptiembre-1931-998622/html/a5692ac7-3664-4749-84da-9837f987e46d_2.html\#I_o_l

Kohan, N. (2020). Paulo Freire más que nunca: una biografía filosófica. Clacso.

Mélich, J.-C. (2020). La sabiduría de lo incierto: lectura y condición humana. Tusquets.

Morrison, T. (2019, 6 de agosto). Lea aquí el discurso antirracista y feminista de Toni Morrison al recoger el Nobel de Literatura. ABC.es. https://www.abc.es/cultura/abci-aqui-discursoantirracista-y-feminista-toni-morrison-recoger-premio-nobel-201908061717_noticia.html

Mouawad, W. (2011). Incendios. Parte I y II de la Tetralogía: la sangre de las promesas. Los Textos de la Capilla.

Ngozi, Ch. (2011). El peligro de la historia única. Penguin Random House.

Osorio, J. (2018). Freire, entre nos. Nuevas Miradas.

Rodríguez-Brandao, C. (2014). El niño que leía el mundo: una historia de personas, de letras y de palabras. Desde Abajo.

Salcedo, J. (2009). Pedagogía de la potencia y didáctica no parametral. Entrevista con Estela Quintar. Revista Interamericana de Educación de Adultos, 31(1), 119-134.

Streck, D. (2008). El diccionario Paulo Freire. Ceaal.

Zemelman, H. (1987). Conocimiento y sujetos sociales. El Colegio de México.

Zuleta, E. (2005). Elogio de la dificultad. Hombre Nuevo Editores. 